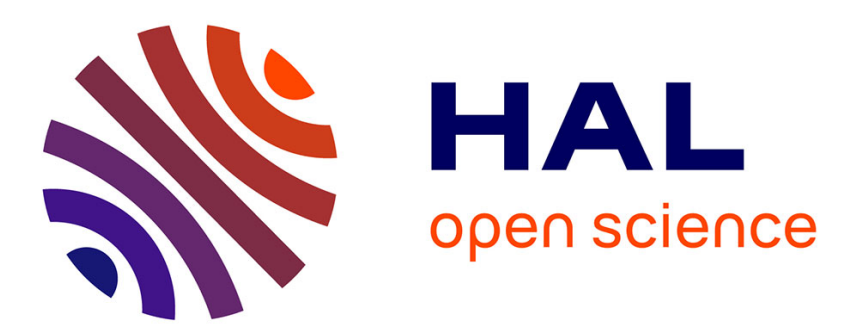

\title{
Molecular dynamic simulation of binary ZrxCu100-x metallic glass thin film growth
}

Lu Xie, Pascal Brault, Anne-Lise Thomann, Larbi Bedra

\section{To cite this version:}

Lu Xie, Pascal Brault, Anne-Lise Thomann, Larbi Bedra. Molecular dynamic simulation of binary ZrxCu100-x metallic glass thin film growth. Applied Surface Science, 2013, 274, pp.164 - 170. hal00797237

\section{HAL Id: hal-00797237 \\ https://hal.science/hal-00797237}

Submitted on 6 Mar 2013

HAL is a multi-disciplinary open access archive for the deposit and dissemination of scientific research documents, whether they are published or not. The documents may come from teaching and research institutions in France or abroad, or from public or private research centers.
L'archive ouverte pluridisciplinaire HAL, est destinée au dépôt et à la diffusion de documents scientifiques de niveau recherche, publiés ou non, émanant des établissements d'enseignement et de recherche français ou étrangers, des laboratoires publics ou privés. 


\title{
Molecular dynamic simulation of binary $\mathrm{Zr}_{\mathrm{x}} \mathrm{Cu}_{100-\mathrm{x}}$ metallic glass thin film growth
}

Lu Xie, Pascal Brault(*), Anne-Lise Thomann, Larbi Bedra

GREMI UMR7344 CNRS Université d'Orléans BP6744, 45067 ORLEANS Cedex 2 France

\begin{abstract}
In this work, we employed classical molecular dynamics simulations model to study $\mathrm{Zr}_{\mathrm{x}} \mathrm{Cu}_{100-\mathrm{x}}(3 \leq$ $\mathrm{x} \leq 95)$ metallic glass films deposited on a silicon (100) substrate. Input data were chosen to fit with the experimental operating conditions of a magnetron sputtering deposition system. The growth evolution is monitored with variable compositions of the incoming atom vapor. The $\mathrm{Zr}-\mathrm{Zr}, \mathrm{Cu}-\mathrm{Cu}$ and $\mathrm{Zr}-\mathrm{Cu}$ interactions are modeled with the Embedded Atom Method (EAM), the Si-Si interaction with Tersoff potential, the $\mathrm{Zr}-\mathrm{Si}$ and $\mathrm{Cu}-\mathrm{Si}$ interactions with Lennard-Jones (12-6) potential. Different film morphology and structure were detected and analyzed when the $\mathrm{Zr}$ to $\mathrm{Cu}$ ratio is varied. The results are compared with X-ray diffraction and Scanning Electron Microscopy analyses of experimentally deposited thin films by magnetron sputter deposition process. Both simulation and experiment results show that the structure of the $\mathrm{Zr}_{\mathrm{x}} \mathrm{Cu}_{100-\mathrm{x}}$ film varies from crystalline to amorphous depending on the elemental composition.
\end{abstract}

(*) Corresponding author: pascal.brault@univ-orleans.fr

Keywords

Molecular dynamics simulation, thin film growth, metallic glass, alloy, sputtering deposition 


\section{Introduction}

Recently, there has been a huge interest in the atomic-level structure and structure-property relationship in metallic glasses (MGs). These materials have been studied for 40 years because of their promising properties belonging to both metals (electron, heat conductivity, ductility...) and glasses (hardness...) [1,2]. To stabilize an amorphous phase in metallic alloys, atomic diffusion must be prevented. This could be achieved by playing with the chemical composition (mixing of elements with different atomic sizes) or by freezing a low ordered phase during the synthesis process [3]. It has been shown that deposition of thin films by condensation onto cold substrates allows stabilizing low ordered structure in metallic systems.

As an example, $\mathrm{ZrCu}$ alloys have attracted interest in recent years, due to its bulk metallic glass properties [4-8], and as amorphous alloy films for its mechanical [9-11] and superconductivity properties [12]. Dudonis et al. [13] prepared thin films with composition in the range of $(5 \leq \mathrm{x} \leq 95)$ by using high working power (490 $\mathrm{W}$ and $1380 \mathrm{~W}$ on $\mathrm{Cu}$ and $\mathrm{Zr}$ targets, respectively) during magnetron sputtering deposition.

Numerous theoretical studies have also been conducted on $\mathrm{Zr}-\mathrm{Cu}$ systems. Sha et al. [14-15] employed atomistic methods for studying $\mathrm{Zr}-\mathrm{Cu}$ MGs forming conditions. Almyras et al. investigated the microstructure of $\mathrm{Zr}_{35} \mathrm{Cu}_{65}$ and $\mathrm{Zr}_{65} \mathrm{Cu}_{35}$ MGs and found that these systems consist of small touching and/or interpenetrating icosahedral-like clusters which results in "supercluster" (SCs) satisfying the system composition[16]. They thus claimed that seeking the equilibrium configuration for interpenetrating ICO-like clusters allows the prediction of the MG microstructure. While bulk amorphous structure is known to be formed under specific synthesis conditions, the 
$\mathrm{ZrCu}$ amorphous thin film growth has not been so much studied. A better understanding of thin film growth can be achieved via simulations and compared to available experimental data as X-ray diffraction patterns. Molecular dynamics (MD) has proven to be a very successful technique for a detailed understanding of growing processes of metal films, allowing us to explore film forming evolution at the atomic level.

In this work we report on results of molecular dynamics simulations and on a structural study of $\mathrm{Zr}_{\mathrm{x}} \mathrm{Cu} 100_{100-\mathrm{x}}$ metal alloy thin films grown by magnetron plasma sputter deposition. The main goal is to investigate the relationship between the composition and the structure.

\section{Experimental}

The $\mathrm{Zr}_{\mathrm{x}} \mathrm{Cu}_{100-\mathrm{x}}$ alloy films were prepared by DC magnetron sputter deposition in argon atmosphere $(0.25 \mathrm{~Pa})$ and at room temperature. Two targets, pure $\mathrm{Cu}$ (purity, 99.999\%) and pure $\mathrm{Zr}$ (purity, 99.999\%), were used at the same time for co-deposition of the alloy films. The distance between the target and the substrate was set to $10 \mathrm{~cm}$. By altering the sputtering power of both targets, $\mathrm{Zr}_{\mathrm{x}} \mathrm{Cu} 100_{100-\mathrm{x}}$ thin films with different compositions were synthesized on Si (100) wafers. Typical deposited thickness was $600 \mathrm{~nm}$. In order to study the structure of the $\mathrm{Zr}_{\mathrm{x}} \mathrm{Cu}_{100-\mathrm{x}}$ metallic films X-ray diffraction analysis $\left(\mathrm{Cu} \mathrm{K}_{\alpha}\right.$ radiation, $\lambda=0.15405 \mathrm{~nm}$, Breg-Brentano geometry) was performed. Microstructure of the deposits was observed on SEM images (Carl Zeiss-Supra40FEG-SEM)

\section{Molecular dynamics simulation details}

\subsection{Potential functions}

MD is a simulation technique for computing the equilibrium and transport properties of a classical 
many-body system. Giving an initial set of positions and velocities of a system of $\mathrm{N}$ atoms, each atom is treated as a point mass and the atomic motion is solved using Newton's equations [17].

The MD package LAMMPS [18] is used to simulate the deposition of atoms. A script driving the LAMMPS code was written for automating the deposition and the relaxation of the system. Implementing suitable interatomic potentials is certainly the most important issue in molecular dynamics simulation. For describing the interaction between $\mathrm{Zr}-\mathrm{Zr}, \mathrm{Zr}-\mathrm{Cu}, \mathrm{Cu}-\mathrm{Cu}$, we use the many-body EAM potential [19-21]. Such a potential is non-pairwise in the sense that it is based on concepts coming from density functional theory, which stipulates in general that the energy of a solid is a unique function of electron density. It is well adapted to simulate the interaction between such metal atoms.

The total energy $\mathrm{E}_{\mathrm{tot}}$ of an atomic system can be expressed as:

$$
\begin{gathered}
\mathrm{E}_{\mathrm{tot}}=\sum_{\mathrm{i}} \mathrm{V}_{\mathrm{i}} \\
\mathrm{V}_{\mathrm{i}}=\frac{1}{2} \sum_{\mathrm{i}} \phi_{\mathrm{ij}}\left(\mathrm{r}_{\mathrm{ij}}\right)+\mathrm{F}\left(\rho_{\mathrm{ij}}\right) \\
\rho_{\mathrm{i}}=\sum_{\mathrm{i} \neq \mathrm{j}} \mathrm{f}_{\mathrm{i}}\left(\mathrm{r}_{\mathrm{ij}}\right)
\end{gathered}
$$

$V_{i}$ is the internal atom energy and $\rho_{i}$ is the electron density associated with atom $i$ due to the presence of other atoms in the system. $F\left(\rho_{i}\right)$ is the energy required to 'embed' the atom $i$ in the electron density $\rho_{\mathrm{i}} . \phi_{\mathrm{ij}}\left(\mathrm{r}_{\mathrm{ij}}\right)$ is a suitable pair potential.

Tersoff [20] Silicon empirical potential is used for describing the interaction between the Si atoms. This potential has been successfully used to investigate the structural, thermal vibration and surface properties of Si [20].

The Tersoff interatomic potential involves both two- and three-body terms: 


$$
\begin{gathered}
E=\sum_{i} V_{i j} \\
\text { Where } V_{i j}=f_{C}\left(r_{i j}\right)\left[f_{R}\left(r_{i j}\right)+b_{i j} f_{A}\left(r_{i j}\right)\right]
\end{gathered}
$$

Here $i$ and $j$ are labels for the interacting atoms. The term $f_{R}$ represents a repulsive pair potential due to electron overlap, while $\mathrm{f}_{\mathrm{A}}$ represents an attractive pair potential associated with bonding. The function $f_{C}$ is merely a smooth cutoff function which limits the range of the potential. The coefficient $b_{\mathrm{ij}}$ (bond order) corresponds to a many-body interaction of the form:

$$
\begin{aligned}
& b_{i j}=\chi_{i j}\left(1+\beta_{i}^{n_{i}} \xi_{i j}^{n_{i}}\right)^{-1 / 2 n_{i}} \\
& \xi_{i j}^{n_{i}}=\sum_{k \neq i, j} f_{C}\left(r_{i k}\right) g\left(\theta_{i j k}\right)
\end{aligned}
$$

where

$$
g\left(\theta_{i j k}\right)=1+\frac{c_{i}^{2}}{d_{i}^{2}}-\frac{c_{i}^{2}}{d_{i}^{2}+\left(h_{i}-\cos \theta_{i j k}\right)^{2}}
$$

And the constants $\chi_{i j}, \beta_{i}, n_{i}, c_{i}, d_{i}$ and $h_{i}$ depend on the atomic species and $\theta_{i j k}$ is the angle between an $\mathrm{i}-\mathrm{j}$ bond and an $\mathrm{i}-\mathrm{k}$ bond. The EAM and Tersoff parameters are implemented in the LAMMPS software.

We use a Lennard-Jones potential for the interactions between deposit atoms and substrate [17]:

$$
\mathrm{V}_{\mathrm{ij}}\left(\mathrm{r}_{\mathrm{ij}}\right)=4 \varepsilon\left[\left(\frac{\sigma}{\mathrm{r}_{\mathrm{ij}}}\right)^{12}-\left(\frac{\sigma}{\mathrm{r}_{\mathrm{ij}}}\right)^{6}\right]
$$

The parameters $\sigma$ and $\varepsilon$ of $\mathrm{LJ}$ potentials of $\mathrm{Zr}, \mathrm{Cu}$ and $\mathrm{Si}$ are summarized in table $1[20,22] . \sigma$ is the distance cancelling the $\mathrm{LJ}$ potential $\mathrm{V}_{\mathrm{ij}}(\sigma)=0$ and $-\varepsilon$ is the well depth of the LJ potential.

\begin{tabular}{|c|c|c|}
\hline Species & $\varepsilon(\mathrm{eV})$ & $\sigma(\AA)$ \\
\hline $\mathrm{Zr}$ & 0.7382 & 2.9318 \\
\hline $\mathrm{Cu}$ & 0.409 & 2.338 \\
\hline
\end{tabular}




\begin{tabular}{|c|l|l|}
\hline $\mathrm{Si}$ & 0.0175 & 3.826 \\
\hline
\end{tabular}

When pair potential parameters for compound materials are not directly available, mixing rules can be used to make approximations [17]. As example, the Lorenz-Berthelot mixing rule is suitable for Lennard-Jones potentials of species $\mathrm{i}$ and $\mathrm{j}$, giving: $\varepsilon_{\mathrm{ij}}=\left(\varepsilon_{\mathrm{i}} \varepsilon_{\mathrm{j}}\right)^{1 / 2}$ and $\sigma_{\mathrm{ij}}=\left(\sigma_{\mathrm{i}}+\sigma_{\mathrm{j}}\right) / 2$

\subsection{Computational model and analysis methods}

MD simulation was carried out in a three dimensional cell, which was periodic only along $\mathrm{x}$ and $\mathrm{y}$ directions. The deposition of each particle is simulated at the NVE ensemble (i.e. the number of particles $\mathrm{N}$, the system volume $\mathrm{V}$ and the total energy $\mathrm{E}$ are kept constant). The dimensions of the Silicon $(100)$ substrate are $(25 \times 25 \times 10) \AA^{3}$. The first two bottom layers of the substrate are fixed (red atoms in figure 1), while the other layers are temperature - controlled layers using a Berendsen thermostat [23].

When an atom is deposited, the system is in a non-equilibrium state. The high energy of the deposited $\mathrm{Zr}$ and $\mathrm{Cu}$ atoms can be dissipated with Berendsen thermostat in the course of simulation to keep the whole temperature around $300 \mathrm{~K}$ (room temperature) corresponding to the value in the experiment. The initial configuration of the deposition model is pictured in figure 1. 

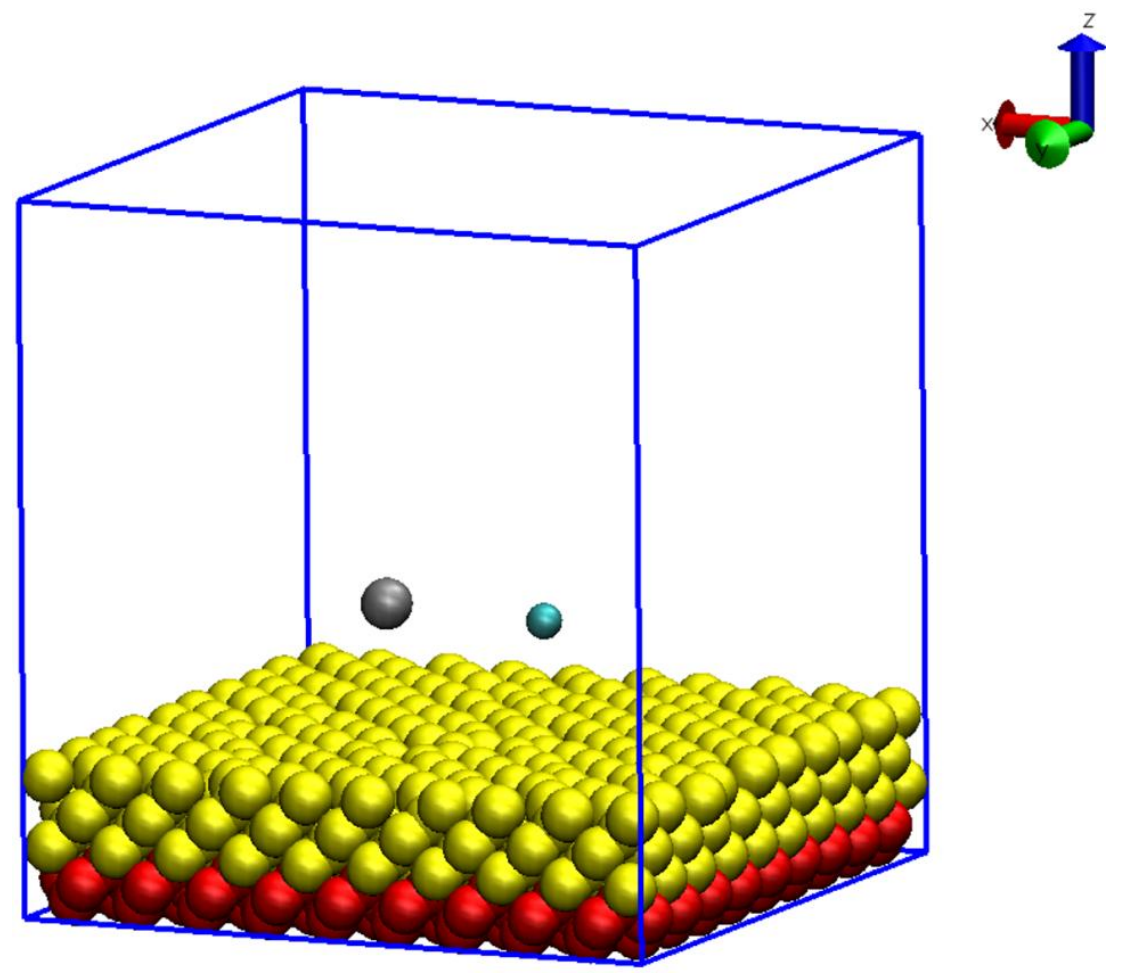

Figure 1.Schematic picture of the deposition model. Grey atom is $\mathrm{Zr}$, blue atom is $\mathrm{Cu}$, yellow atoms are moving Si atoms, red atoms are Si fixed atoms.

The $\mathrm{Zr}$ and $\mathrm{Cu}$ atoms with the six different ratios are randomly deposited on the substrate (one atom per $2 \mathrm{ps}$ ). Each atom is placed in the vacuum slab at a random position from 5 to $7 \AA$ above the surface.

The mean kinetic energy of incoming atoms are calculated according to the modification of Thompson formula [24]:

$$
\begin{gathered}
\mathrm{f}(\mathrm{E}) \propto \frac{1-\left(\frac{\mathrm{E}_{\mathrm{coh}}+\mathrm{E}}{\gamma \mathrm{E}_{\mathrm{Ar}^{+}}}\right)^{\frac{1}{2}}}{\mathrm{E}^{2}\left(1+\frac{\mathrm{E}_{\mathrm{coh}}}{\mathrm{E}}\right)^{3}} \\
\mathrm{E}_{\mathrm{F}}=\left(\mathrm{E}-\mathrm{k}_{\mathrm{B}} \mathrm{T}_{\mathrm{g}}\right) \exp \left[\mathrm{n} \ln \left(\mathrm{E}_{\mathrm{f}} / \mathrm{E}_{\mathrm{i}}\right)\right]+\mathrm{k}_{\mathrm{B}} \mathrm{T}_{\mathrm{g}}
\end{gathered}
$$

$E_{f} / E_{i}=1-\gamma / 2$ is the ratio of energies after and before a collision, [25] where $\gamma=4 \frac{m_{g} m_{s}}{\left(m_{g}+m_{s}\right)^{2}}$ where $\mathrm{m}_{\mathrm{g}}$ and $\mathrm{m}_{\mathrm{s}}$ stand for gas atom (Argon here) and sputtered atom ( $\mathrm{Zr}$ or $\mathrm{Cu}$ here) masses respectively, and $n=d p \tau / k_{B} T_{G}$. E is the energy of the sputtered particles as they leave the target, $T_{g}$ is the 
sputtering gas temperature, $\mathrm{n}$ is the number of collisions that take place in the gas, $\mathrm{d}$ is the traveled distance, $\mathrm{p}$ is the sputtering gas pressure, and $\tau$ is the collision cross section assuming hard core interactions. To calculate the energy loss of sputtered atoms with the gas atoms, a Maxwell-Boltzmann (MB) distribution at $\mathrm{T}_{\mathrm{g}}$ is fixed for the gas (in our conditions $\mathrm{T}_{\mathrm{g}}=300 \mathrm{~K}$ ). Because we search for the complete distribution of sputtered atoms, we replace $\mathrm{k}_{\mathrm{B}} \mathrm{T}_{\mathrm{g}}$ by $\mathrm{Eg}$, a particular value in the gas distribution. Thus for each Eg in the MB gas distribution, the energy loss is calculated for a fixed value of the kinetic energy $\mathrm{E}$ of a sputtered atom. This is repeated for each $\mathrm{E}$ in the Thompson distribution and weighted by the collision probability, which is simply the product of $\mathrm{f}(\mathrm{E})$ and the $\mathrm{MB}$ distribution at $\mathrm{T}_{\mathrm{g}}$. [24].

At an argon pressure being of $0.25 \mathrm{~Pa}$ and a target to substrate distance of $9 \mathrm{~cm}$, the mean kinetic energy of $\mathrm{Zr}$ and $\mathrm{Cu}$ were found equal to $7.65 \mathrm{eV}$ and $6.67 \mathrm{eV}$, respectively. For the MD simulations, the velocities of the $\mathrm{Zr} / \mathrm{Cu}$ deposited atoms are randomly sampled from a Maxwell-Boltzmann distribution with the most probable energy $7.65 \mathrm{eV}$ and $6.67 \mathrm{eV}$ separately.. The timestep is chosen to be $1 \mathrm{fs}$. Every 10000 timesteps, 5 atoms are released towards the surface, i.e. one atom per 2 ps on average. This time is enough for thermal relaxation to take place with Berendsen thermostat.

After simulation of $\mathrm{Zr}-\mathrm{Cu}$ metallic film growth has been completed, the partial radial distribution functions (PRDF) were employed to determine the correlation between the atoms. The PRDF can be expressed as

$$
\mathrm{g}_{\alpha \beta}(\mathrm{r})=\frac{\mathrm{V}}{\mathrm{N}_{\alpha} \mathrm{N}_{\beta}}\left\langle\sum_{\mathrm{i}}^{\mathrm{N}} \sum_{\mathrm{j} \neq \mathrm{i}}^{\mathrm{N}} \delta\left(\mathrm{r}-\mathrm{r}_{\mathrm{ij}}\right)\right\rangle
$$

Where $\mathrm{V}$ is the volume of the system, $\mathrm{N}_{\alpha}$ and $\mathrm{N}_{\beta}$ are the number of atoms $\alpha$ and $\beta$, respectively, $\mathrm{r}_{\mathrm{ij}}$ represents the distance between atoms $\mathrm{i}$ and $\mathrm{j}, \delta\left(\mathrm{r}-\mathrm{r}_{\mathrm{ij}}\right)$ is the Dirac delta function, and the angular brackets represent the time average. The radial distribution function RDF of atom $\mathrm{i}$ is denoted by 
$g_{i}(r)$ and is the sum of the PRDFs for atom $i$ to atom $j$, written as $g_{i}(r)=\sum_{j} g_{i j}(r)$. Similarly, the total RDF for the whole system is computed as $\mathrm{g}_{\text {tot }}(\mathrm{r})=\sum_{\mathrm{i}} \mathrm{g}_{\mathrm{i}}(\mathrm{r})$

Finally, the simulated XRDs was employed to analyze the phase of $\mathrm{Zr}-\mathrm{Cu}$ metallic film and to compare with the experiment data directly. In most radiation scattering experiments, the objective is to obtain information that characterizes either intramolecular or intermolecular structure. In such cases, variation of the scattered intensity with angle is the quantity of main interest, whereas the absolute intensity is of no concern. Thus, ignoring all intensity scale factors and correction factors appropriate for the geometry of the scattering apparatus, the amplitude and intensity of radiation scattered coherently from an arbitrary set of $\mathrm{n}$ atoms may be written as:

$$
\begin{gathered}
\mathrm{F}(\mathbf{Q})=\sum_{\mathrm{j}=1}^{\mathrm{n}} \mathrm{f}_{\mathrm{i}} \exp \left(\mathbf{Q} \cdot \mathbf{r}_{\mathrm{j}}\right) \\
\mathrm{I}(\mathrm{Q})=\mathrm{F}(\mathbf{Q}) * \mathrm{~F}(\mathbf{Q})=\sum_{\mathrm{j}=1}^{\mathrm{n}} \sum_{\mathrm{k}=1}^{\mathrm{n}} \mathrm{f}_{\mathrm{i}} \mathrm{f}_{\mathrm{k}} \cos \left(\mathrm{i} \mathbf{Q} \cdot \mathbf{r}_{\mathrm{jk}}\right) \\
\mathrm{Q}=\frac{2 \pi}{\mathrm{d}}=\frac{2 \sin \theta}{\mathrm{n} \lambda} \\
\mathrm{f}_{\mathrm{i}}=\int \rho_{\mathrm{i}} \mathbf{r} \exp (-2 \pi \mathrm{i} \mathbf{Q} \mathbf{r}) \mathrm{d}^{3} \mathbf{r}
\end{gathered}
$$

Where $\rho_{i}$ is the density of atom $i, r$ is the position vector, and Q is the scattering vector (Bragg's law), $\mathrm{f}_{\mathrm{i}}$ is the atomic scattering factors for the radiation used, and $\mathrm{r}_{\mathrm{jk}}$ denotes the vector connecting atoms $\mathrm{j}$ and $\mathrm{k}$.

\section{Results and discussions}

In order to study the influence of the elemental composition on the crystallographic properties of the thin films, MD simulations of $\mathrm{Zr}_{\mathrm{x}} \mathrm{Cu}_{100-\mathrm{x}}$ metallic films grown on a crystalline $\mathrm{Si}(100)$ substrate 
were carried out at operating conditions similar to that describing magnetron co-sputtering process. The $\mathrm{Zr}$ metal content in the film ranged from $3 \%$ (i.e. $\mathrm{Zr}_{3} \mathrm{Cu}_{97}$ ) to $95 \%$ (i.e. $\mathrm{Zr}_{95} \mathrm{Cu}_{5}$ ) which has been found by properly preparing the incoming vapor composition. The film composition was found to be close to the vapor composition, which in turn means that sticking coefficients are close to each other.

The films grew to approximately $5 \sim 7.5 \mathrm{~nm}$. Snapshots of the deposited layers on the $\operatorname{Si}(100)$ substrate are presented in figure 2. 
$\mathrm{Zr3Cu97}$ (280/8617 at.)

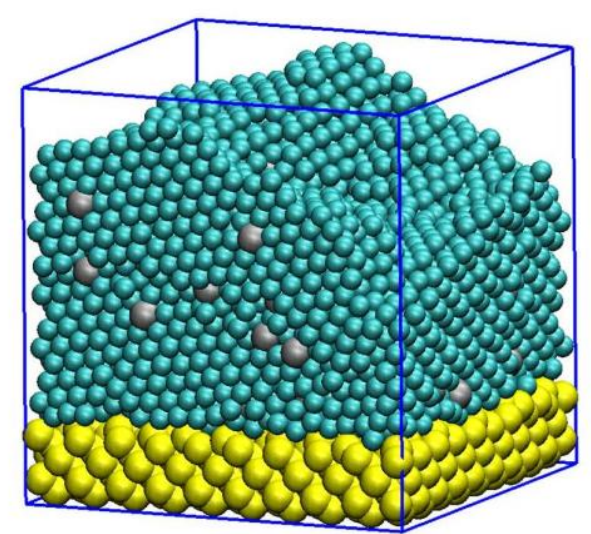

\section{Zr46Cu54 (4180/4955 at.)}

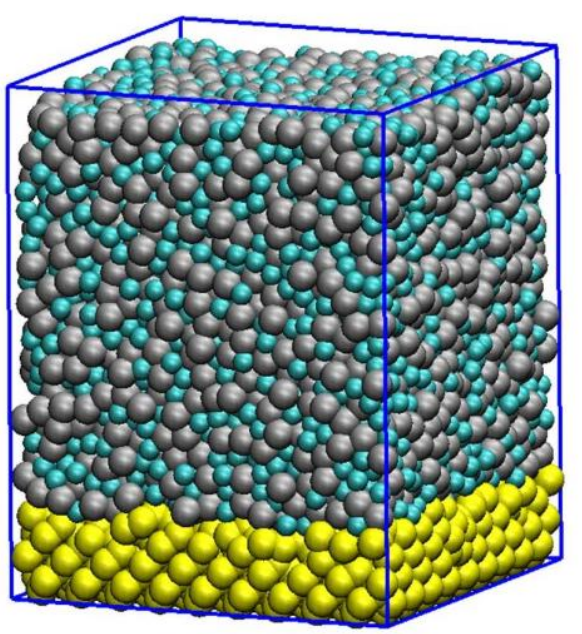

Zr73Cu27 (6733/2523 at.)

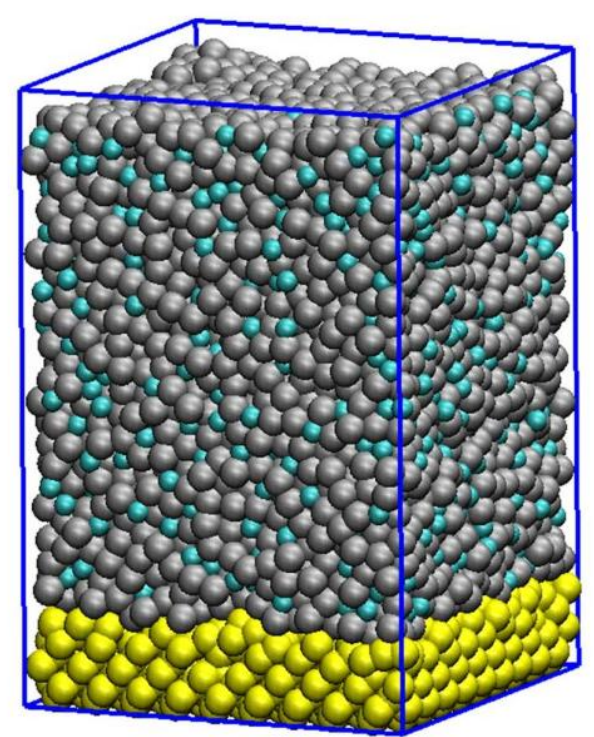

Zr20Cu80 (1769/7174 at.)

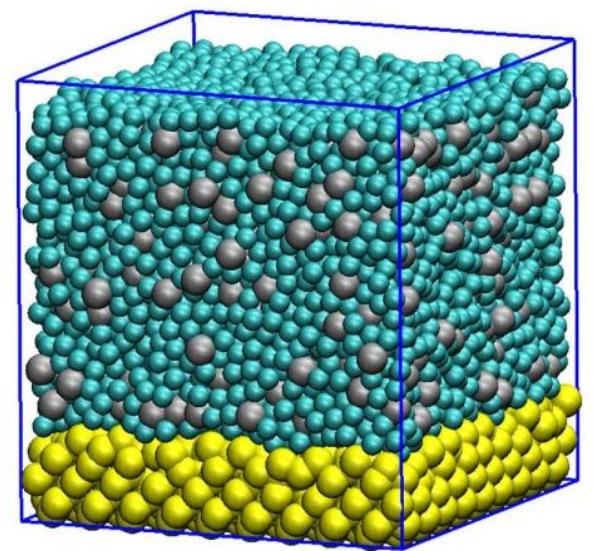

$\mathrm{Zr55Cu45} \mathrm{(5102/4089} \mathrm{at.)}$

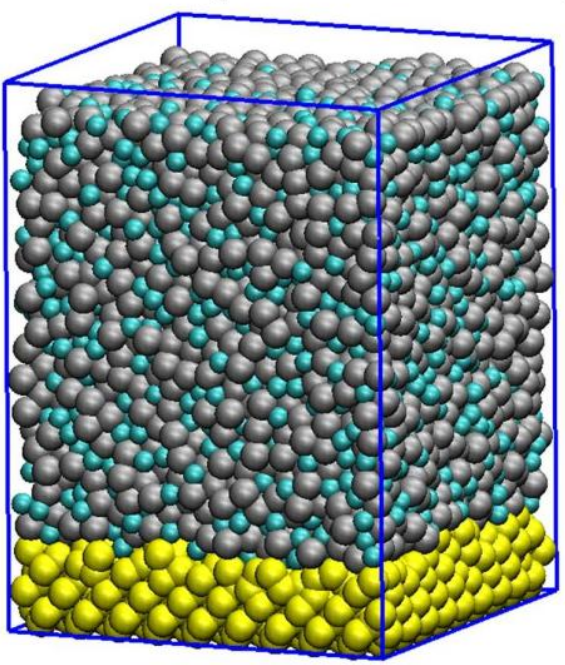

\section{Zr95Cu5 (8864/437 at.)}

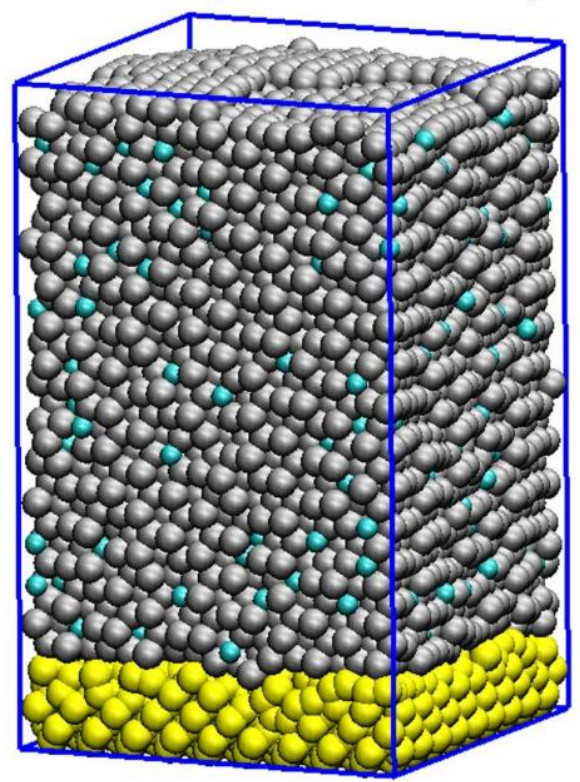

Figure 2. Snapshot of $\mathrm{Zr}$-Cu coatings deposited on Si(100) substrate at different ratios of $\mathrm{Zr}$ and $\mathrm{Cu}$ atoms. The numbers in brackets are the $\mathrm{Zr}$ and $\mathrm{Cu}$ atom numbers respectively). The colors have the same meaning than in Fig.1 
Based on these simulations, the partial radial distribution function (PRDF) for the system $\mathrm{Zr}_{\mathrm{x}} \mathrm{Cu}_{100-\mathrm{x}}$ was calculated for each case. The $\mathrm{Zr}-\mathrm{Cu}, \mathrm{Zr}-\mathrm{Zr}$ and $\mathrm{Cu}-\mathrm{Cu}$ PRDFs at 3\%, 20\%, 46\%, 55\%, $73 \%$ and $95 \% \mathrm{Zr}$ metal contents are presented in figures 3-5 respectively.

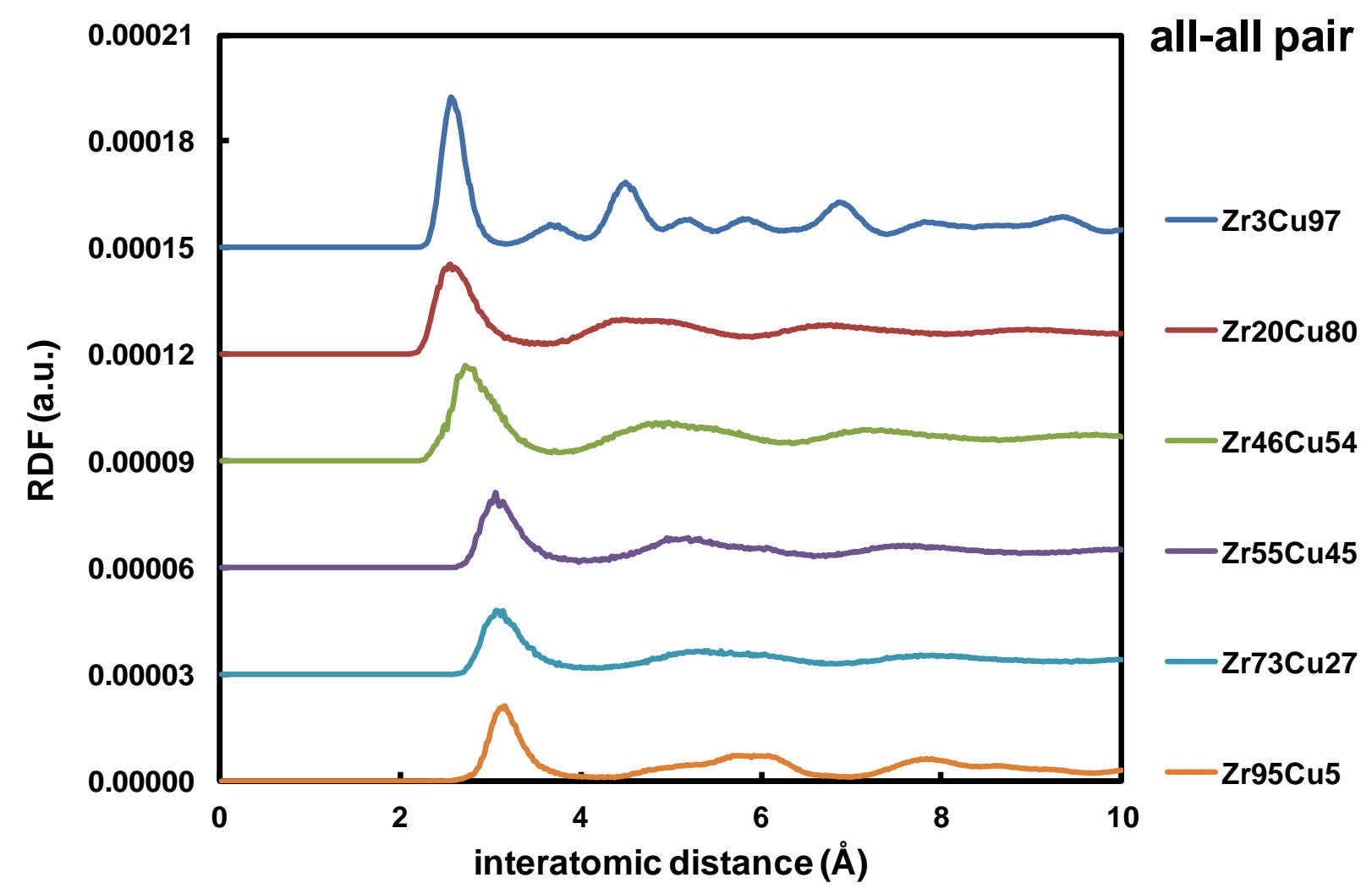

Figure. 3 Total RDFs for $\mathrm{Zr}_{x} \mathrm{Cu}_{100-x}$ alloys, individual curves corresponding to different alloy compositions are displaced vertically for clarity. 


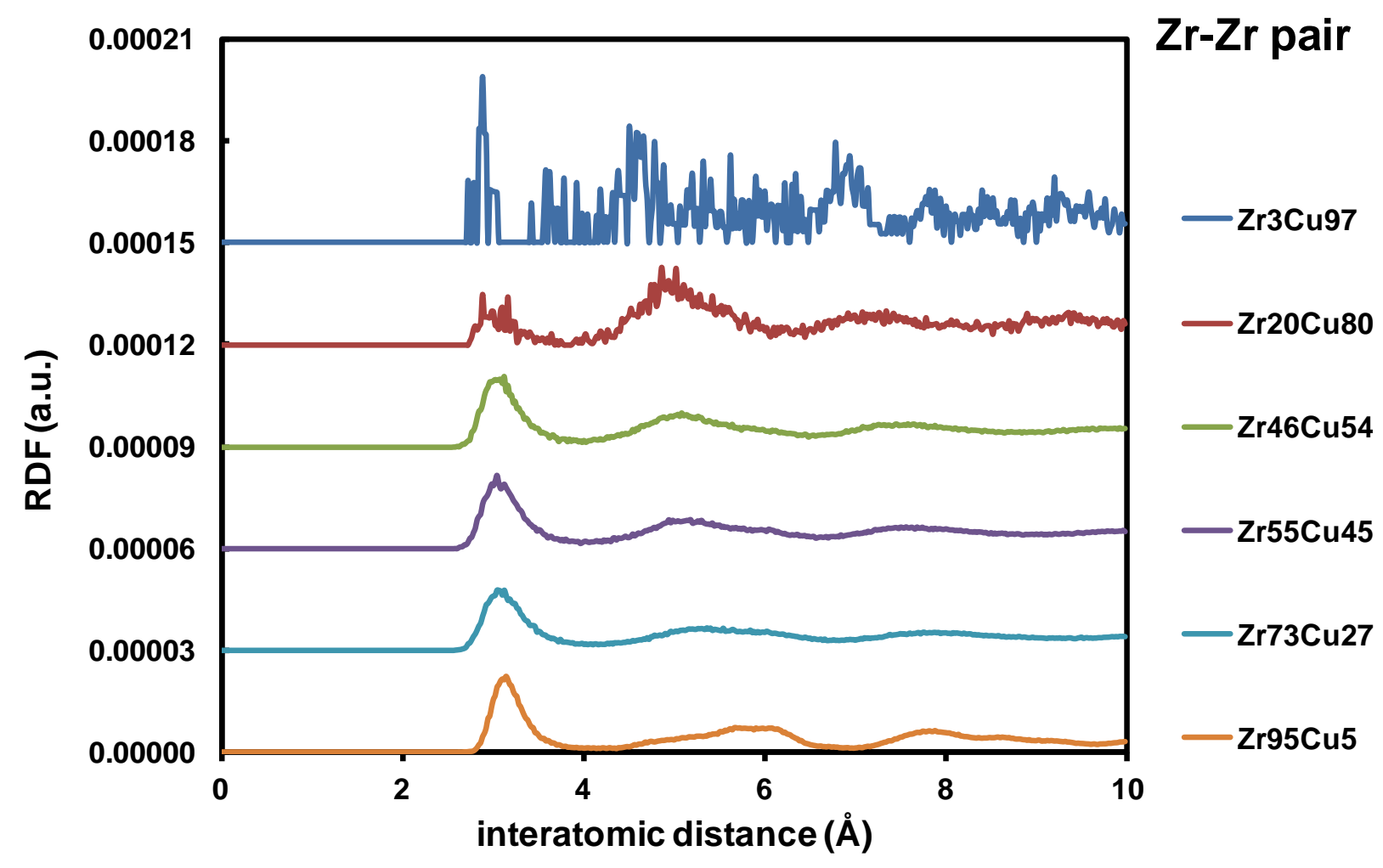

Figure. 4 RDFs for $\mathrm{Zr}$-Zr for $\mathrm{Zr}_{x} \mathrm{Cu}_{100-x}$ alloys, individual curves corresponding to different alloys are displaced vertically for clarity.

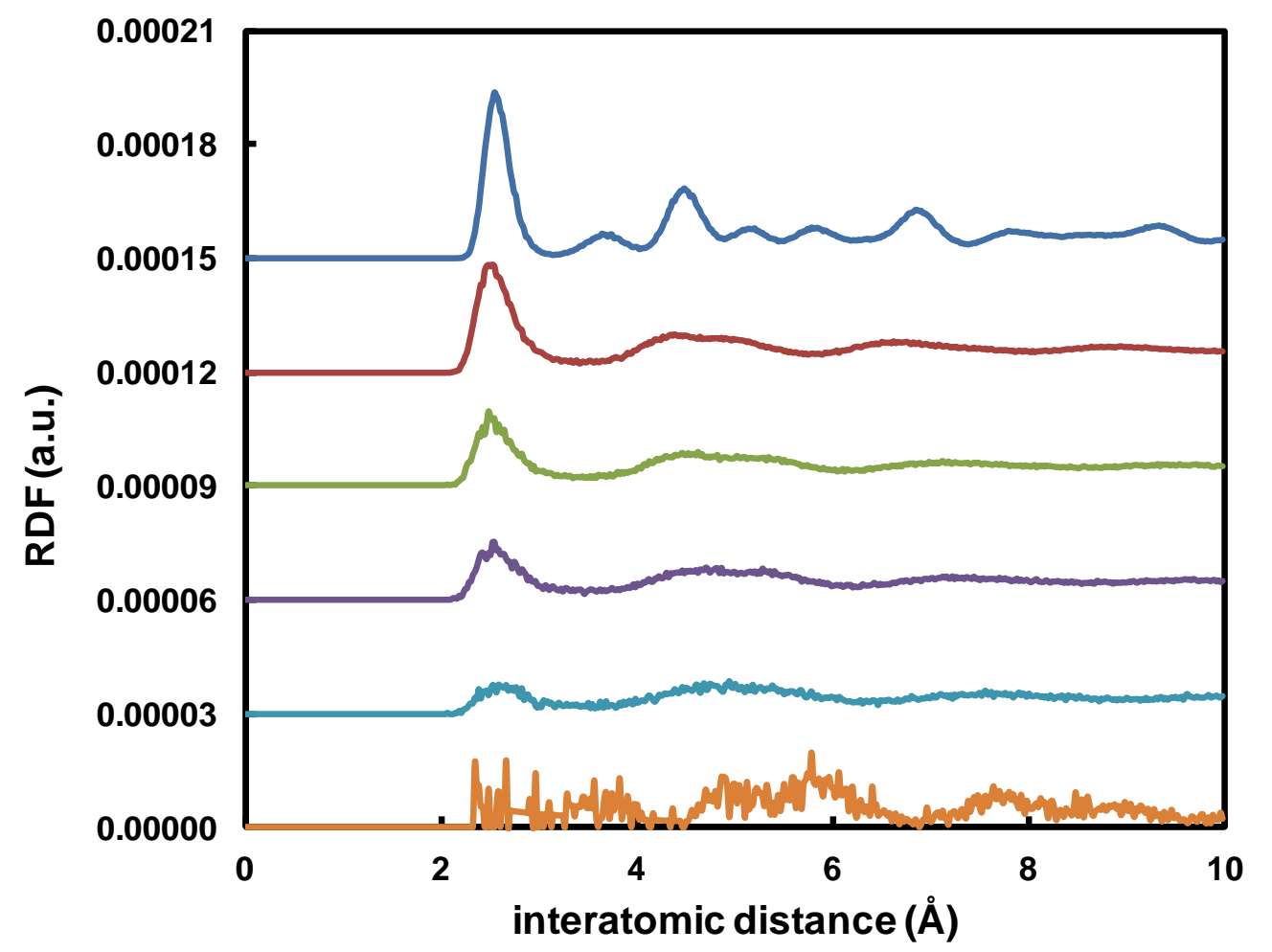

Cu-Cu pair

- Zr3Cu97

- Zr20Cu80

- Zr46Cu54

- Zr55Cu45

- Zr73Cu27

- Zr95Cu5

Figure. $5 \mathrm{RDFs}$ for $\mathrm{Cu}$-Cu for $\mathrm{Zr}_{x} \mathrm{Cu} u_{100-x}$ alloys, individual curves corresponding to different alloys are displaced vertically for clarity. 
At low or high concentrations of $\mathrm{Zr}$, i.e. $\mathrm{Zr}_{3} \mathrm{Cu}_{97}$ or $\mathrm{Zr}_{95} \mathrm{Cu}_{5}$, the calculated PRDFs show outstanding peaks which can be assumed as crystalline structure representing $\mathrm{Cu}$ and $\mathrm{Zr}$ separately, because the intensity and position of the peaks are very similar to those of the $\mathrm{Cu}$ and $\mathrm{Zr}$ crystals (table 1). This is also clear from the snapshots of the films at the corresponding $\mathrm{Zr}$ concentrations presented in figure 2: the cross-sections of $\mathrm{Zr}_{3} \mathrm{Cu}_{97}$ and $\mathrm{Zr}_{95} \mathrm{Cu}_{5}$ have well crystal structure. For the $\mathrm{Zr}$ contents between $3 \%$ and $95 \%$, the intensity of the PRDF peaks decreases dramatically. Especially, the first and second peaks become broader and split while the other peaks are fading away quickly, which represents an amorphous structure. This is in agreement with the visual observation in figures 2 (from $\mathrm{Zr}_{20} \mathrm{Cu}_{80}$ to $\mathrm{Zr}_{73} \mathrm{Cu}_{27}$ ). Besides, The $\mathrm{RDF}$ of the system exhibits a distinct first peak indicating that there exists a strong short-range order (SRO). We also observe that the first peak shifts toward larger radial distance values when increasing $\mathrm{Zr}$ concentrations. This was expected since the $\mathrm{Zr}-\mathrm{Zr}$ first neighbor distance is larger than that of $\mathrm{Cu}$. The splitting of the peak is also visible indicating a progressive change from a $\mathrm{Zr}$ predominant to $\mathrm{Cu}$ predominant film.

Table 1 The four nearest neighbor distances in $\mathrm{Zr}$ and $\mathrm{Cu}$ bulk crystals. Lattice constants for $\mathrm{Zr}$ and $C u$ are respectively $a_{Z r}=3.23 \AA, c_{Z r}=5.15 \AA$ and $a_{C u}=3.61 \AA$.

\begin{tabular}{|c|c|c|c|c|c|}
\hline $\begin{array}{c}\text { Crystal } \\
\text { name }\end{array}$ & Structure & First neighbor $(\AA)$ & $\begin{array}{c}\text { Second } \\
\text { neighbor }(\AA)\end{array}$ & $\begin{array}{c}\text { Third neighbor } \\
(\AA)\end{array}$ & Fourth neighbor $(\AA)$ \\
\hline $\mathrm{Zr}$ & $\mathrm{hcp}$ & $\mathrm{a}_{\mathrm{Zr}}=3.23$ & $\sqrt{2} \mathrm{a}_{\mathrm{Zr}}=4.53$ & $\mathrm{c}_{\mathrm{Zr}}=5.15$ & $\sqrt{2} \mathrm{c}_{\mathrm{Zr}}=5.57$ \\
\hline $\mathrm{Cu}$ & $\mathrm{fcc}$ & $\frac{\mathrm{a}_{\mathrm{Cu}}}{\sqrt{2}}=2.55$ & $\mathrm{a}_{\mathrm{Cu}}=3.61$ & $\sqrt{\frac{3}{2}} \mathrm{a}_{\mathrm{Cu}}=4.42$ & $\sqrt{2} \mathrm{a}_{\mathrm{Cu}}=5.10$ \\
\hline
\end{tabular}

Figs. 4 and 5 show the PRDFs for like bonds, $\mathrm{Zr}-\mathrm{Zr}$ and $\mathrm{Cu}-\mathrm{Cu}$ in these systems, respectively. As illustrated in Fig. 4, like bonds exhibit strong sensitivity to atomic concentrations. For example, in 
$\mathrm{Zr}-\mathrm{Zr}$ PRDFs, at low $\mathrm{Zr}$ concentration $\left(\mathrm{Zr}_{3} \mathrm{Cu}_{97}\right)$, the PRDF does not exhibited specific structure showing $\mathrm{Zr}$ atoms are well randomly dispersed in $\mathrm{Cu}$ background without correlations. This is confirmed when looking at the corresponding snapshots. When the $\mathrm{Zr}$ concentration increases, the third and fourth peak slowly appears and become "higher and narrower" indicating the Zr-Zr's phase changing from amorphous state to crystalline. On the contrary, the $\mathrm{Cu}-\mathrm{Cu}$ PRDF shows a stronger SRO in the $\mathrm{Cu}$-rich film and a progressive change from crystal to amorphous when the $\%$ of $\mathrm{Cu}$ decreases as it can be seen in Fig. 4 and 5.

In summary, the PRDFs show that an amorphous structure of the films is observed in a wide compositional range i.e. when $20 \leq x \leq 73$. .

For comparison with simulations, figure 6 shows the intensity of the XRD $\theta-2 \theta$ peaks as a function of the $\mathrm{Zr}$ metal content. At the $\mathrm{Zr}$ concentration of $3 \%$ and $95 \%, \mathrm{Zr}_{\mathrm{x}} \mathrm{Cu}_{100-\mathrm{x}}$ films are crystalline which agrees with the present PRDF calculations reported in figure 3-5. As the $\mathrm{Zr}$ concentration increases from $20 \%$ to $73 \%$, a shift of peaks towards small angles $\left(2 \theta=41.8^{\circ}, 38.7^{\circ} 37.4^{\circ}\right.$, and $35.9^{\circ}$ ) is observed. Meanwhile, all of these patterns consist of a broad halo peak, indicating a low ordered structure. It seems that $\mathrm{Zr}$ and $\mathrm{Cu}$ atoms are inserted in the main element matrix and form a solid solution. Distortion of the lattice parameter due to the different atomic size leads to a lowering of the crystallinity.

Three of the experimentally deposited films, i.e. at $3 \%, 72 \%$ and $95 \% \mathrm{Zr}$ metal content, were observed by SEM and the images of the films (surface and cross-section) are presented in figures 8(a)-(c), respectively. The films at 3\% $\mathrm{Zr}$ and 95\% (figure 8(a), (b), (c), (d)) exhibit grains of about $50 \mathrm{~nm}$ and columnar structure is visible on the cross-section micrographs. On the contrary $\mathrm{Zr}_{73} \mathrm{Cu}_{27}$ film (figure (c), (d)) seems relatively dense and featureless which could correspond to an 
amorphous structure. SEM observations are thus in agreement with XRD results.

Ignoring all intensity scale factors and correction factors appropriate for the geometry of the scattering apparatus, the calculated $\mathrm{X}$-ray intensities vs. 2-Theta of $\mathrm{Zr}_{\mathrm{x}} \mathrm{Cu}_{100-\mathrm{x}}$ simulated films are shown in figure 7 . By comparing both XRD plot sets, it can be observed that the peak positions in the simulated XRD are close to that detected in the experimental XRD patterns. For crystalline expected conditions the peaks are broad due to finite size simulations. Also a shift between experimental and simulated positions is observed (table 2) certainly due to finite size effects of the simulations, and possibly due to some layer strain in the experimental films. On the other hand, the peak intensities are very different between simulations and experiments. This is due to the difference in layer thickness, thus in the total atom number. And also the ratio of different structural phases can be different too. At this stage, the comparison is only qualitative.

Table 2 the $2 \theta$ position of first XRD peak for $\mathrm{ZrCu}$ alloy in the experiment and simulation

Experiment
\begin{tabular}{|c|c|c|c|c|c|c|}
\hline $\mathrm{Zr}-\mathrm{Cu}$ & $\mathrm{Zr}_{3} \mathrm{Cu}_{97}$ & $\mathrm{Zr}_{20} \mathrm{Cu}_{80}$ & $\mathrm{Zr}_{46} \mathrm{Cu}_{54}$ & $\mathrm{Zr}_{55} \mathrm{Cu}_{45}$ & $\mathrm{Zr}_{73} \mathrm{Cu}_{27}$ & $\mathrm{Zr}_{95} \mathrm{Cu}_{5}$ \\
\hline first peak & 43.2 & 41.8 & 38.7 & 37.4 & 35.9 & 34.5 \\
\hline
\end{tabular}

Simulation
\begin{tabular}{|c|c|c|c|c|c|c|}
\hline $\mathrm{Zr}-\mathrm{Cu}$ & $\mathrm{Zr}_{3} \mathrm{Cu}_{97}$ & $\mathrm{Zr}_{20} \mathrm{Cu}_{80}$ & $\mathrm{Zr}_{46} \mathrm{Cu}_{54}$ & $\mathrm{Zr}_{55} \mathrm{Cu}_{45}$ & $\mathrm{Zr}_{73} \mathrm{Cu}_{27}$ & $\mathrm{Zr}_{95} \mathrm{Cu}_{5}$ \\
\hline first peak & 42.2 & 41.7 & 38.65 & 37.7 & 36.1 & 35.55 \\
\hline
\end{tabular}




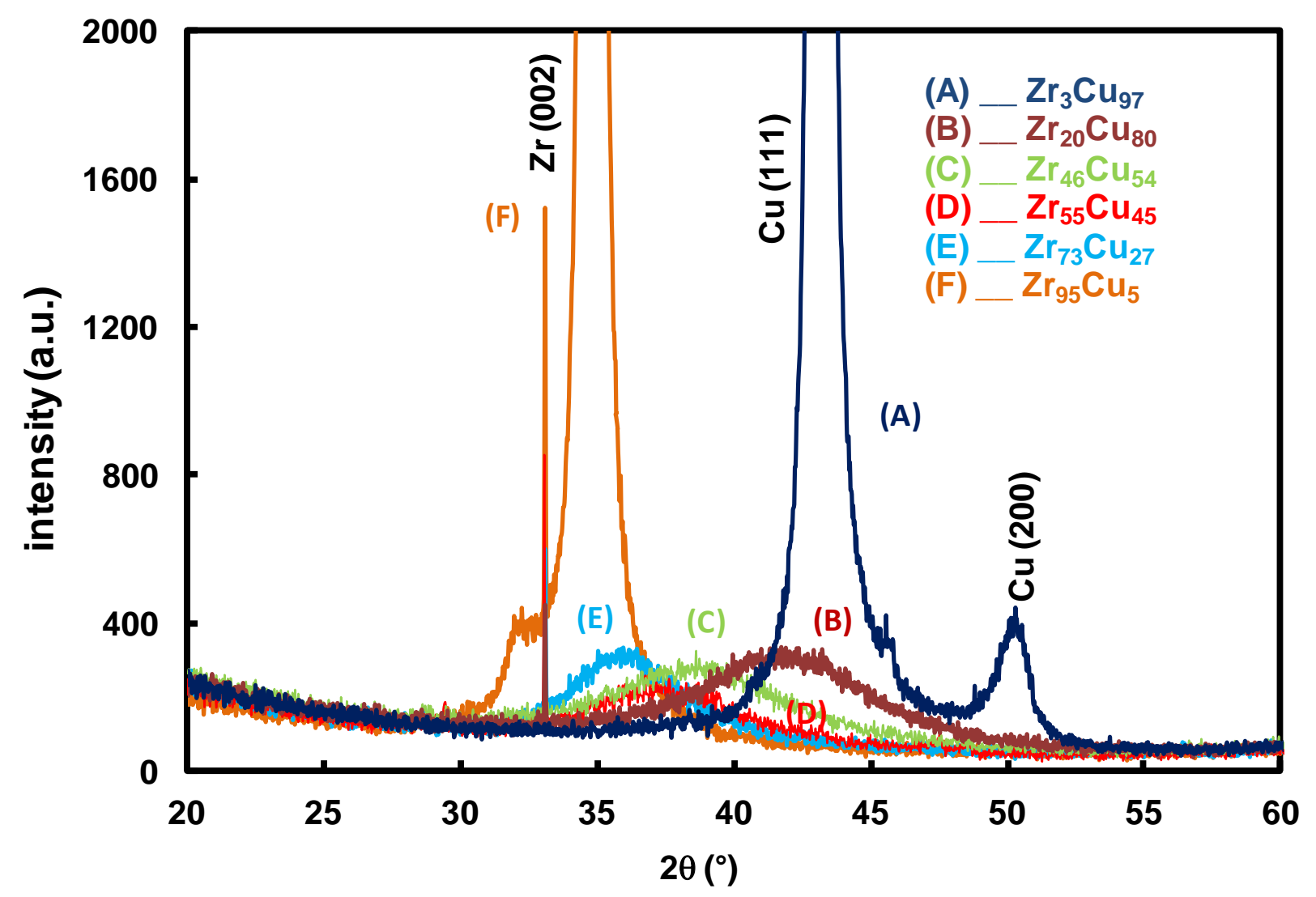

Figure 6. XRD patterns of $\mathrm{Zr}_{x} \mathrm{Cu} u_{100-x}$ film sputtered at $300 \mathrm{~K}$ with different compositions in the experiment 


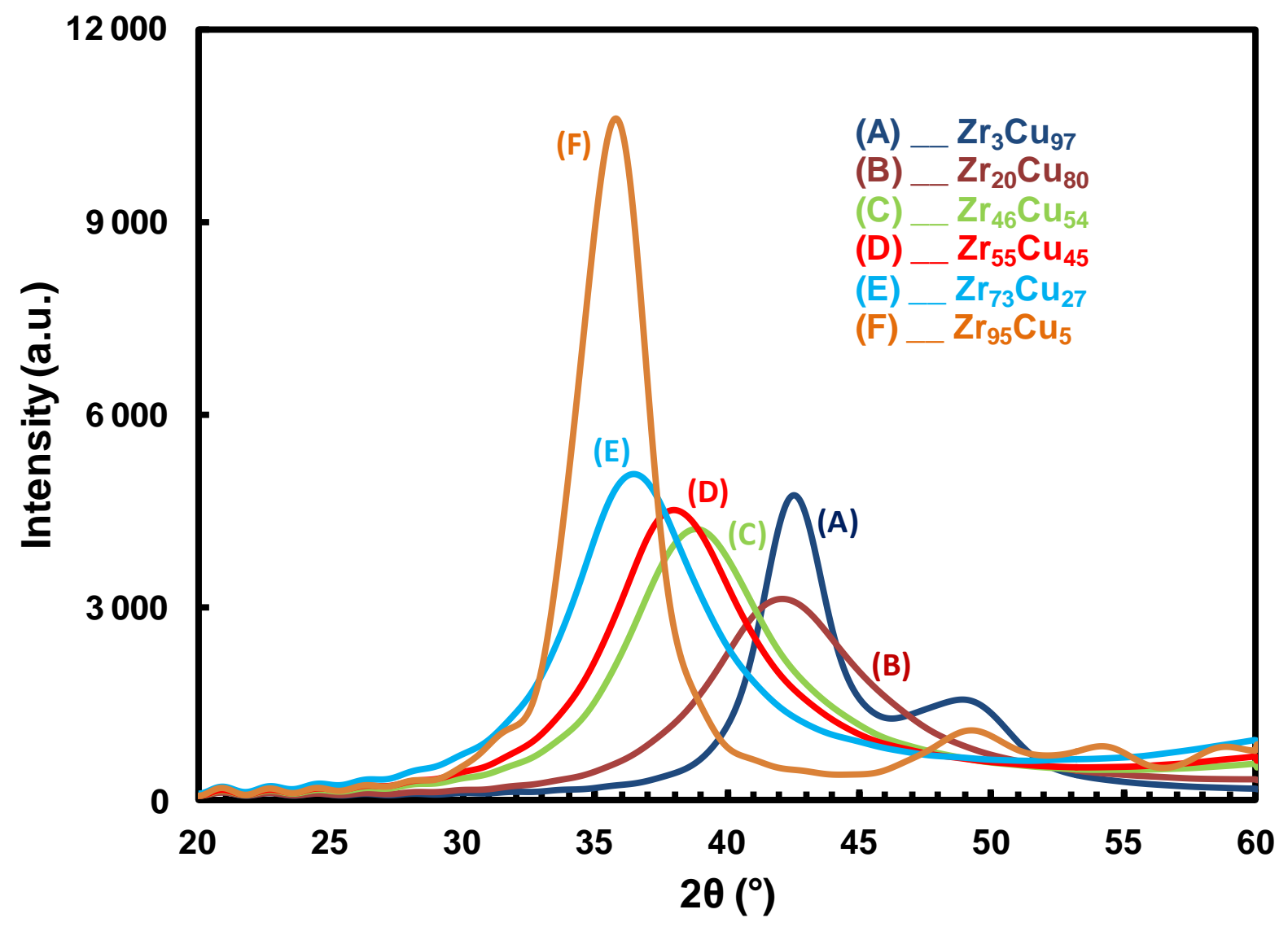

Figure 7. $\mathrm{X}$-Ray intensity vs. $2 \theta$ of $\mathrm{Zr}_{x} \mathrm{Cu}_{100-x}$ film with different compositions in the simulation
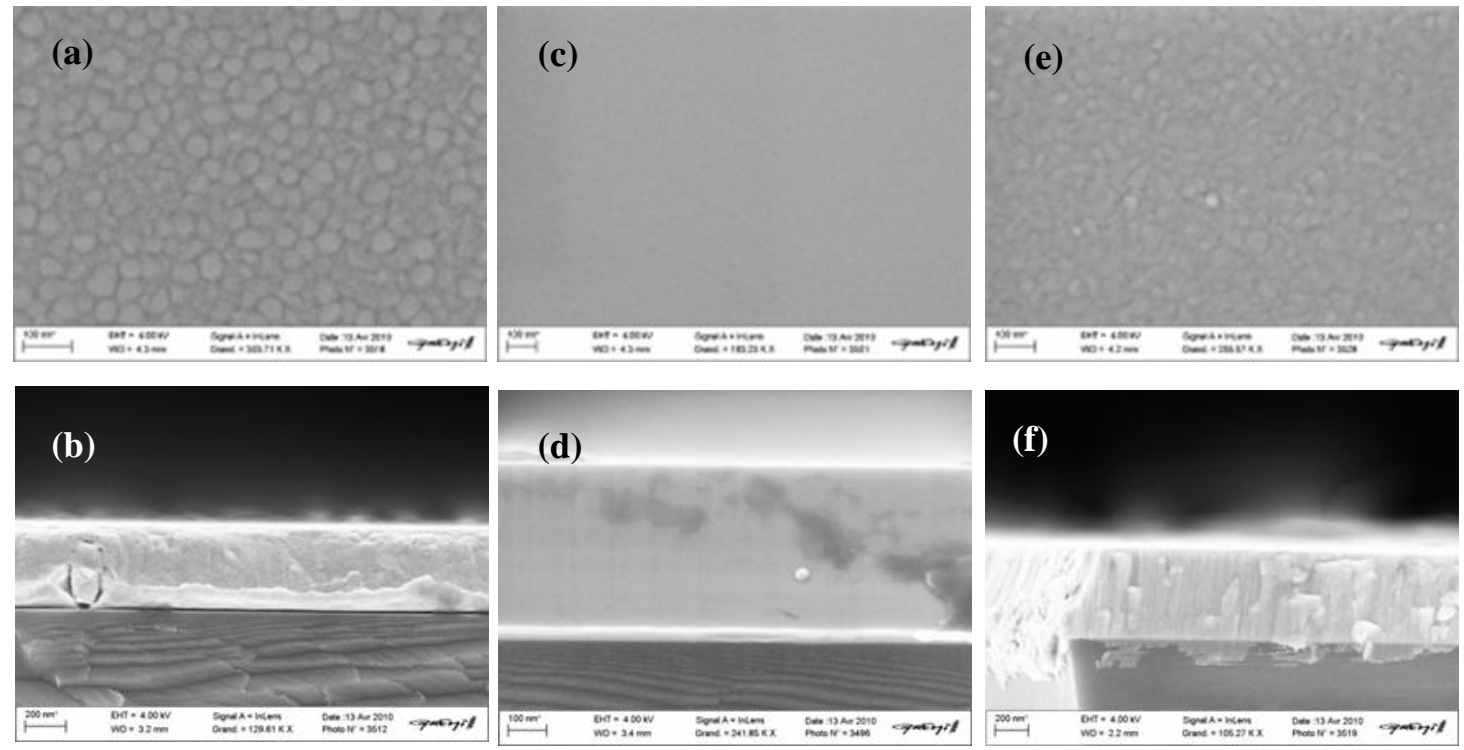

Figure 8. SEM images of $\mathrm{Zr}$-Cu films deposited on an Si(100) at 3\% (a,b), 73\% (c, b) and 95\% (c, d) Zr metal content; image (a), (c), (e) is about the surface, image (b), $(d),(f)$ is about cross section. 


\section{Conclusions}

$\mathrm{Zr}_{\mathrm{x}} \mathrm{Cu}_{100-\mathrm{x}}$ thin films grown by magnetron co-sputtering process were studied by MD simulations using initial conditions similar to the experimental operating ones. The crystallinity of the films was analyzed by calculated PRDFs and XRD. The results show that films containing large amount of one of the element (higher than 80\%) are crystallized, whereas for intermediate compositions low ordered phase is evidenced. This trend is due to chemical disorder, since both atoms seem to be incorporated in the same lattice (solid solution) which induces distortion of the parameter. The value of the later is found to lie between that of both pure metals. The results from the MD simulations were compared with XRD and SEM analyses of the experimentally deposited thin films. The experimental results also showed that the structure of the films changes from crystalline at a high or low $\mathrm{Zr}$ content to amorphous at intermediate $\mathrm{Zr}$ contents, ranging from 20 to $75 \%$. The good agreement between experimental results and simulation is of particular interest: it proves that modeling at the atomic level allows predicting the structure of hundreds of nanometer thick films grown by magnetron sputter deposition. MD may thus be a helpful tool for the design of new alloys.

\section{References}

[1] N. Mattern, Microstructure Analysis in Materials Science, 15-17 (2005)

[2] T. Masumoto, Sci. Rep. RITU A39 (1994) 91

[3] Y. Kawamura, H. Kato, A. Inoue, T. Masumoto, International journal of powder metallurgy, 33 (1997) 50-61.

[4] Y.Q. Cheng, E. Ma, Prog. Mater.Sci. 56 (2011) 379-473.

[5] Tang M B, Zhao D Q, Pan M X, WH Wang, Chin. Phys. Lett. 21 (2004) 901

[6] Wang D, Li Y, Sun B B,Sui M L, Lu K, Ma E., Appl. Phys. Lett. 84 (2004) 4029 
[7] Yu P, Bai H Y and Wang W H, J. Mater. Res. 21 (2006) 1674

[8] Kenoufi A, Bailey N P and Schiotz J, Adv. Eng. Mater. 9 (2007) 505

[9] Xu D H, Lohwongwatana B, Duan G, W. L. Johnson, C. Garland, Acta Mater. 52 (2004) 2621

[10] Das J, Tang M B, Kim K B, Theissmann R, Baier F, Wang WH, and Eckert J,Phys. Rev. Lett. 94 (2005) 205501

[11] Musil J, Daniel R Surf. Coat. Technol. 166 (2003) 243

[12] Karpe N, Bttiger J, Krog J P, Noerdström A., Rapp O et al, Thin Solid Films 275 (1996) 82

[13] Dudonis J, Brucas R and Miniotas A 1996 Thin Solid Films 275164

[14] Z.D. Sha, Y.P. Feng, Y. Li, Appl. Phys. Lett. 96 (2010) 061903.

[15] Z.D. Sha, Y.W. Zhang, Y.P. Feng, Y. Li, J. Alloys Compound. 509 (2011) 8319-8322.

[16] G.A. Almyras, C.E. Lekka, N. Mattern, G.A. Evangelakisa, Scripta Mater. 62 (2010) 33-36.

[17] Frenkel D and Smith B 2002 Understanding Molecular Simulation (New York: Academic)

[18] S. J. Plimpton and A. P. Thompson, MRS Bulletin, 37(2012). 513-521

[19] Daw M S, Foiles S M and Baskes M I, Mater. Sci. Reports 9 (1993) 251-310

[20] D. B. Graves, P. Brault, J. Phys. D 42 (2009) 194011

[21] X. W. Zhou, R. A. Johnson and H. N. G. Wadley, Physical Review B 69(2004) 144113

[22] S. Zhen, G.J. Davies, Phys. Stat. Sol. (a) 78 (1983) 595-605.

[23] H.J.C. Berendsen, J.P.M. Postma, W.F. van Gunsteren, A. DiNola, J. Haak, J. Chem. Phys., 81 (1984) 3684 .

[24] K. Meyer, I. K. Shuller, C. M. Falco J. Appl. Phys. 52 (1981) 5803

[25] A. Gras-Marti, J. A. Valles-Abarca, J. Appl. Phys. 54 (1983) 1071 


\section{Table caption}

Table 1 The four nearest neighbor distances in $\mathrm{Zr}$ and $\mathrm{Cu}$ bulk crystals. Lattice constants for Zr and $C u$ are respectively $a_{Z r}=3.23 \AA, c_{Z r}=5.15 \AA$ and $a_{C u}=3.61 \AA$.

\begin{tabular}{|c|c|c|c|c|c|}
\hline $\begin{array}{c}\text { Crystal } \\
\text { name }\end{array}$ & Structure & First neighbor $(\AA)$ & $\begin{array}{c}\text { Second } \\
\text { neighbor }(\AA)\end{array}$ & $\begin{array}{c}\text { Third neighbor } \\
(\AA)\end{array}$ & Fourth neighbor $(\AA)$ \\
\hline $\mathrm{Zr}$ & $\mathrm{hcp}$ & $\mathrm{a}_{\mathrm{Zr}}=3.23$ & $\sqrt{2} \mathrm{a}_{\mathrm{Zr}}=4.53$ & $\mathrm{c}_{\mathrm{Zr}}=5.15$ & $\sqrt{2} \mathrm{c}_{\mathrm{Zr}}=5.57$ \\
\hline $\mathrm{Cu}$ & $\mathrm{fcc}$ & $\frac{\mathrm{a}_{\mathrm{Cu}}}{\sqrt{2}}=2.55$ & $\mathrm{a}_{\mathrm{Cu}}=3.61$ & $\sqrt{\frac{3}{2}} \mathrm{a}_{\mathrm{Cu}}=4.42$ & $\sqrt{3} \mathrm{a}_{\mathrm{Cu}}=5.10$ \\
\hline
\end{tabular}

Table 2 the $2 \theta$ position of first XRD peak for $\mathrm{ZrCu}$ alloy in the experiment and simulation

Experiment

Unit: $2 \theta$ (deg)

\begin{tabular}{|c|c|c|c|c|c|c|}
\hline $\mathrm{Zr}-\mathrm{Cu}$ & $\mathrm{Zr}_{3} \mathrm{Cu}_{97}$ & $\mathrm{Zr}_{20} \mathrm{Cu}_{80}$ & $\mathrm{Zr}_{46} \mathrm{Cu}_{54}$ & $\mathrm{Zr}_{55} \mathrm{Cu}_{45}$ & $\mathrm{Zr}_{73} \mathrm{Cu}_{27}$ & $\mathrm{Zr}_{95} \mathrm{Cu}_{5}$ \\
\hline first peak & 43.2 & 41.8 & 38.7 & 37.4 & 35.9 & 34.5 \\
\hline
\end{tabular}

Simulation

Unit: $2 \theta(\mathrm{deg})$

\begin{tabular}{|c|c|c|c|c|c|c|}
\hline $\mathrm{Zr}-\mathrm{Cu}$ & $\mathrm{Zr}_{3} \mathrm{Cu}_{97}$ & $\mathrm{Zr}_{20} \mathrm{Cu}_{80}$ & $\mathrm{Zr}_{46} \mathrm{Cu}_{54}$ & $\mathrm{Zr}_{55} \mathrm{Cu}_{45}$ & $\mathrm{Zr}_{73} \mathrm{Cu}_{27}$ & $\mathrm{Zr}_{95} \mathrm{Cu}_{5}$ \\
\hline first peak & 42.2 & 41.7 & 38.65 & 37.7 & 36.1 & 35.55 \\
\hline
\end{tabular}




\section{Figure captions}

Figure 1 : Schematic picture of the deposition model. Grey atom is $\mathrm{Zr}$, blue atom is $\mathrm{Cu}$, yellow atoms are moving $\mathrm{Si}$ atoms, red atoms are Si fixed atoms.

Figure 2 : Snapshot of $\mathrm{Zr}-\mathrm{Cu}$ coatings deposited on $\mathrm{Si}(100)$ substrate at different ratios of $\mathrm{Zr}$ and $\mathrm{Cu}$ atoms. The numbers in brackets are the $\mathrm{Zr}$ and $\mathrm{Cu}$ atom numbers respectively). The colors have the same meaning than in Fig.1

Figure 3 : Total $\mathrm{RDFs}$ for $\mathrm{Zr}_{\mathrm{x}} \mathrm{Cu}_{100-\mathrm{x}}$ alloys, individual curves corresponding to different alloy compositions are displaced vertically for clarity.

Figure. 4 PRDFs for $\mathrm{Zr}-\mathrm{Zr}$ for $\mathrm{Zr}_{\mathrm{x}} \mathrm{Cu}_{100-\mathrm{x}}$ alloys, individual curves corresponding to different alloys are displaced vertically for clarity

Figure 5 : PRDFs for $\mathrm{Cu}-\mathrm{Cu}$ for $\mathrm{Zr}_{\mathrm{x}} \mathrm{Cu}_{100-\mathrm{x}}$ alloys, individual curves corresponding to different alloys are displaced vertically for clarity.

Figure 6 : XRD patterns of $\mathrm{Zr}_{\mathrm{x}} \mathrm{Cu}_{100-\mathrm{x}}$ film sputtered at $300 \mathrm{~K}$ with different compositions in the experiment

Figure 7 : XRay intensity vs. $2 \theta$ of $\mathrm{Zr}_{\mathrm{x}} \mathrm{Cu}_{100-\mathrm{x}}$ film with different compositions in the simulation

Figure 8 : SEM images of $\mathrm{Zr}-\mathrm{Cu}$ films deposited on an $\operatorname{Si}(100)$ at 3\% (a, b), 73\% (c, b) and 95\% (c, d) $\mathrm{Zr}$ metal content; image (a), (c), (e) is about the surface, image (b), (d), (f) is about cross section. 